\title{
DETECTION GENETIC VARIABILITY OF CASTOR GENOTYPES (RICINUS COMMUNIS L.) USING SSR MARKERS
}

\section{Vivodík Martin*, Petrovičová Lenka, Balážová Želmíra, Gálová Zdenka}

Slovak University of Agriculture in Nitra, Faculty of Biotechnology and Food Sciences, Department of Biochemistry and Biotechnology

Knowledge of genetic variability is important for breeding programs to provide the basis for developing desirable genotypes. The aim of this study was to assess genetic diversity within the set of 60 ricin genotypes using 5 SSR primers. Five SSR primers revealed a total of 38 alleles ranging from 5 to 10 alleles per locus with a mean value of 7.60 alleles per locus. The PIC values ranged from 0.776 (Rco40) to 0.872 (Rco33) with an average value of 0.843 and the DI value ranged from 0.786 (Rco40) to 0.876 (Rco33) with an average value of 0.849 . The dendrogram of genetic similarity was constructed, based on UPGMA algorithm. The hierarchical cluster analysis divided castor genotypes into five main clusters. In this experiment, SSRs markers proved to be a high informative and usefull tool in genetic diversity research for the distinguishing and characterization of close related varieties.

Keywords: castor; genetic diversity; molecular markers; simple sequence repeat; SSR

\section{Introduction}

Castor (Ricinus communis L.) is a cross-pollinated diploid $(2 n=2 x=20)$ species belonging to the family Euphorbiaceae and genus Ricinus. Castor is an important industrial oilseed crop. Its seed oil has multifarious applications in production of wide industrial products ranging from medicines to lower molecular weight aviation fuels, fuel additives, biopolymers and biodiesel (Ogunniyi, 2006). Castor seeds contain around $50-55 \%$ oil which is rich in an unusual hydroxy fatty acid, ricinoleicacid which constitutes about $80-90 \%$ of the total fatty acids (Jeong and Park, 2009).

Knowledge of genetic variability is important for breeding programs to provide the basis for developing desirable genotypes. Genetic variability in castor bean has been studied using molecular techniques, including amplified fragment length polymorphism (AFLP) (Pecina-Quintero et al., 2013), random amplified polymorphism DNA (RAPD) (Vivodík et al., 2014), single nucleotide polymorphism (SNP) markers (Foster et al., 2010), simple sequence repeat (SSR) (Tan et al., 2014), start codon targeted polymorphism (SCoT) and inter simple sequencerepeat (ISSR) (Kallamadi et al., 2015). Pecina-Quintero et al. (2013) used four different AFLP primer pairs. In total, the four combinations of selective primers amplified 430 products, of which 228 were polymorphic. Vivodík et al. (2014) used 8 RAPD markers to detect genetic variability among the set of 40 castor genotypes. Foster et al. (2010) analyzed the population genetics of $R$. communis in a worldwide collection of plants from

*Corresponding author: Martin Vivodík, Slovak University of Agriculture in Nitra, Faculty of Biotechnology and Food Sciences, Department of Biochemistry and Biotechnology, $\triangle$ vivodikmartin@gmail.com 
germplasm and determined the population genetic structure of 676 samples using single nucleotide polymorphisms (SNPs) at 48 loci.

The goal of Tan et al. (2014) was to develop a more complete panel of SSR markers that can be used to construct a genetic map of castor bean and to examine genetic variation in this plant. The present investigation of Kallamadi et al. (2015) has been undertaken to assess the extent of genetic diversity in 31 accessions of castor using ISSR and SCOT primers. Among the DNA markers, SSR markers have been used intensively to analyse genetic diversity. So far, several investigations on the discrimination between crop genotypes using SSR markers have been carried out by Fayyaz et al. (2014), Kanwal et al. (2014), Polat et al. (2015).

The goals of this study were to examine the effectiveness of SSR markers for analysis of genetic diversity of castor and to study genetic relationships among 60 castor accessions using 5 SSR markers.

\section{Materials and methodology}

\section{Plant material and DNA extraction}

A total 60 castor genotypes (called RM-45 - RM-105) obtained from the breeding station Zeainvent Trnava Ltd. (Slovakia), were used in this study. DNA of 60 genotypes of castor was extracted from leaves of 10 day old seedlings using the Gene JET Plant Genomic DNA Purification Mini Kit. Each sample was diluted to $20 \mathrm{ng}$ with TE buffer (10 mM Tris- $\mathrm{HCl}, \mathrm{pH} 8.0$ and $0.1 \mathrm{mM} \mathrm{EDTA}, \mathrm{pH} 8.0$ ), stored at $-20{ }^{\circ} \mathrm{C}$ and resolved on agarose gel with the standard lambda DNA for determining the DNA concentration.

\section{SSR amplification}

Amplification of SSR fragments was performed according to Bajay et al. $(2009,2011)$ (Table 1.). Polymerase chain reaction (PCR) were performed in $25 \mu \mathrm{l}$ of a mixture containing $10.5 \mu \mathrm{l} \mathrm{H}_{2} \mathrm{O}$, $12.0 \mu \mathrm{l}$ Master Mix (Genei, Bangalore, India), $0.75 \mu \mathrm{l}$ of each primer (10 pmol) and $1 \mu \mathrm{l}$ DNA (100 ng). Amplification was performed in a programmed thermocycler (Biometra, Germany) and amplification program consisted of an initial denaturing step at $94{ }^{\circ} \mathrm{C}$ for $1 \mathrm{~min}$, followed by 35 cycles of amplification [ $94^{\circ} \mathrm{C}$ ( $\left.1 \mathrm{~min}\right), 1 \mathrm{~min}$ at the specific annealing temperature of each primer pair (Table 1), $72{ }^{\circ} \mathrm{C}(1 \mathrm{~min})$ ] and a final elongation step at $72{ }^{\circ} \mathrm{C}$ for $10 \mathrm{~min}$. Amplification products were confirmed by electrophoresis in $7 \%$ denaturing polyacrylamide gels and silver stained and documented using gel documentation system Grab-It 1D for Windows.

Table 1 List of SSR primers

\begin{tabular}{|c|c|c|c|}
\hline Marker name & $\mathrm{Ta},{ }^{\circ} \mathrm{C}$ & Repeat motif & Sequence of the primer $\left(5^{\prime}-3^{\prime}\right)$ \\
\hline Rco33 & 60 & $(\mathrm{TCT}) 11$ & $\begin{array}{l}\text { F: ACATACATGCAGGGAGACCA } \\
\text { R:TCTGCTTTAATGGCTGATCG }\end{array}$ \\
\hline Rco34 & 60 & (GT)11 & $\begin{array}{l}\text { F:TCGGTTAAGGGTATGGGTTG } \\
\text { R: CACACTTCATTTCGCAGACC }\end{array}$ \\
\hline Rco35 & 60 & (AG)16 & $\begin{array}{l}\text { F: GGAAGAATTGGGTTGGAAGT } \\
\text { R: AACAAACACAGGTGCATCAT }\end{array}$ \\
\hline Rco40 & 60 & (TC) $5(\mathrm{CT}) 7$ & $\begin{array}{c}\text { F: AACTGGATAAAGGGGTATTTGG } \\
\text { R: GCTTTTTGGTAGCAGGTTTGA }\end{array}$ \\
\hline Rco41 & 60 & $(\mathrm{CT}) 17(\mathrm{CA}) 11$ & $\begin{array}{l}\text { F: CATGTTGTTTTTGGGCAGCTC } \\
\text { R: CGTTCACACTCATCAATCCA }\end{array}$ \\
\hline
\end{tabular}

Source: Bajay et al., 2009, 2011 


\section{Data analysis}

The SSR bands were scored as present (1) or absent (0), each of which was treated as an independent character regardless of its intensity.

A dendrogram based on hierarchical cluster analysis using the unweighted pair group method with arithmetic average (UPGMA) with the SPSS professional statistics version 17 software package was constructed. For the assessment of the polymorphism between genotypes ricin and usability SSR markers in their differentiation we used diversity index (DI), the probability of identity (PI) and polymorphic information content (PIC).

\section{Results and discussion}

The development of molecular markers has opened up numerous possibilities for their application in plant breeding. Five specific microsatellite primer pairs revealed a total of 38 alleles ranging from 5 (Rco40) to 10 (Rco33) alleles per locus with a mean value of 7.60 alleles per locus (Table 2). Resulting from the number and frequency of alleles, diversity index (DI), polymorphic information content (PIC) and probabilities of identity (PI) were calculated (Table 2). The PIC values ranged from 0.776 (Rco40) to 0.872 (Rco33) with an average value of 0.843 and the DI value ranged from 0.786 (Rco40) to 0.876 (Rco33) with an average value of 0.849 (Table 2).

Table 2 The statistical characteristics of the SSR markers used in castor

\begin{tabular}{|l|c|c|c|c|}
\hline Marker name & Number of alleles & DI & PIC & PI \\
\hline Rco33 & 10 & 0.876 & 0.872 & 0.004 \\
\hline Rco34 & 7 & 0.842 & 0.835 & 0.005 \\
\hline Rco35 & 8 & 0.871 & 0.867 & 0.002 \\
\hline Rco40 & 5 & 0.786 & 0.776 & 0.012 \\
\hline Rco41 & 8 & 0.870 & 0.866 & 0.002 \\
\hline Average & 7.60 & 0.849 & 0.843 & 0.005 \\
\hline
\end{tabular}

$\mathrm{DI}$ - diversity index, PIC - polymorphic information content, $\mathrm{PI}$ - probability of identity

The dendrogram of genetic relationships among 60 castor cultivars based on SSR markers is presented in Figure 1. The hierarchical cluster analysis showed that the castor genotypes were divided into five main clusters. Cluster 1 contained 10 genotypes, cluster 2 included 10 genotypes of ricin and cluster 3 contained 6 genotypes of ricin. Cluster 4 included 17 genotypes and cluster 5 contained 17 genotypes (Figure 1). We could not distinguish 4 genotypes grouped in cluster 1, RM-63 - RM-64 and RM-50 - RM-51 and 2 genotypes grouped in cluster 5, RM-45 - RM-46, which are genetically the closest. We can assume that they have close genetic background (Figure 1). 


\section{Genotypes}

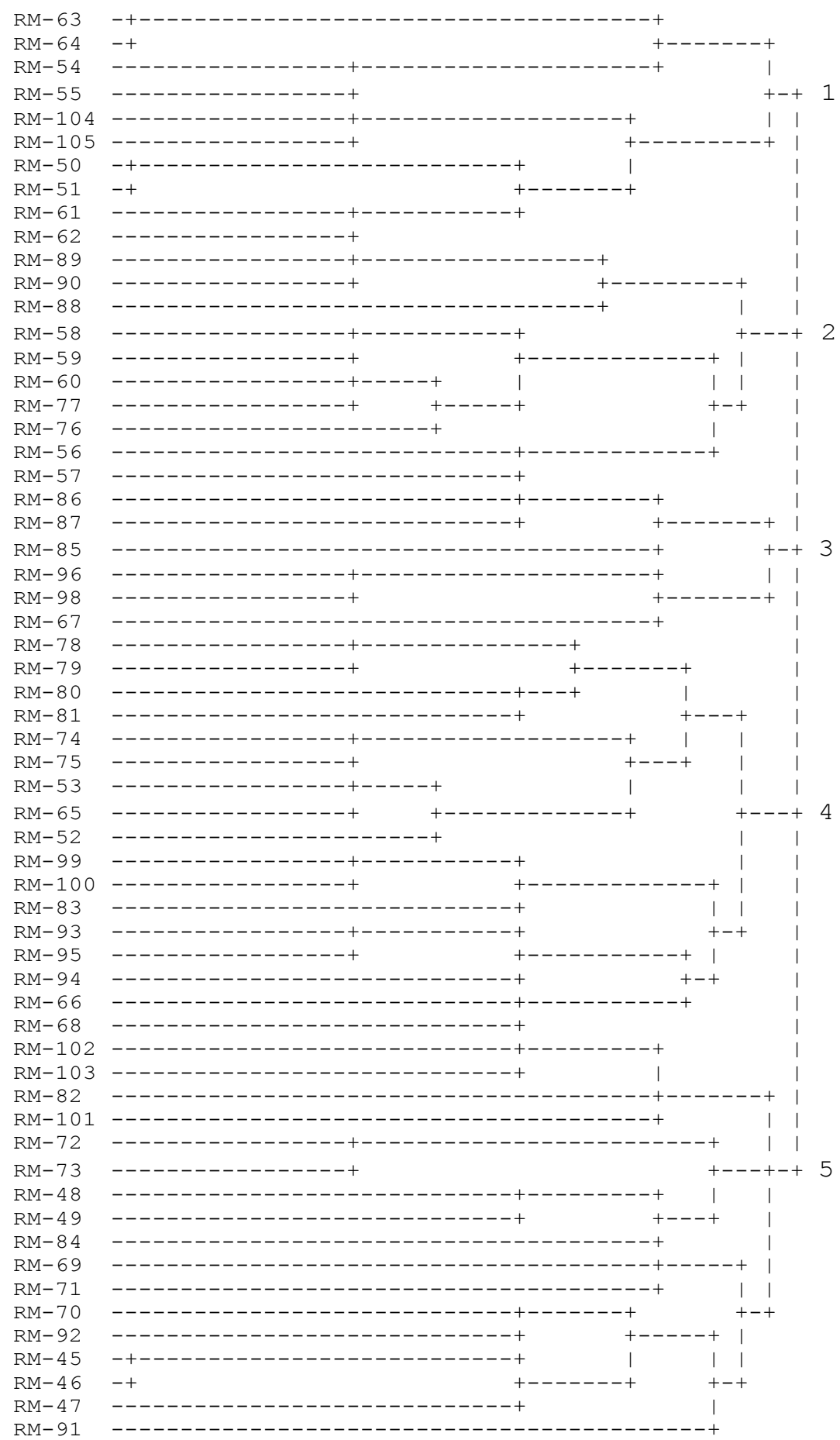

Figure 1 Dendrogram of 60 castor genotypes prepared based on 5 SSR markers 


\section{Conclusions}

In conclusion, a high level of genetic diversity exists among the castor accessions were analyzed. According to analysis, the collection of 60 diverse accessions of castor bean was clustered into five clusters. We could not distinguish 6 genotypes grouped in cluster 1 and 5 which are genetically the closest. A SSR marker system is a rapid and reliable method for cultivar identification that might also be used in quality control in certified seed production programs, to identify sources of seed contamination, and to maintain pure germplasm collections.

\section{Acknowledgments}

This work was funded by European Community under project ITMS 26220220180: Building Research Centre "AgroBioTech" (50\%) and KEGA project No 021SPU-4/2015 (50\%).

\section{References}

Bajay, M.M., Pinheiro, J.B., Batista, C.E.A., Nobrega, M.B.M., Zucchi, M.I. 2009. Development and characterization of microsatellite markers for castor (Ricinus communis L.), an important oleaginous species for biodiesel production. Conserv. Genet., vol. 1, p. 237-239. http://dx.doi.org/10.3732/ ajb.1000395

Bajay, M.M., Zucchi, M.I., Kiihl, T.A.M., Batista, C.E.A., Monteiro, M., Pinheiro, J.B. 2011. Development of a novel set of microsatellite markers for Castor bean, Ricinus communis (Euphorbiaceae). Am. J. Bot., vol. 98, p. 87-89. http://dx.doi.org/10.3732/ajb.1000395

Fayyaz, L., Farhatullah-Rabbani, M.A., Iqbal, S., Kanwal, M., Nawaz, I. 2014. Genetic diversity analysis of Brassica napus/Brassica campestris progenies using microsatellite markers. Pak. J. Bot., vol. 46, no. 3, p. 779-787.

Jeong, G.T., Park, D.H. 2009. Optimization of biodiesel production from castor oilusing response surface methodology. Appl. Biochem. Biotech., vol. 156, p. 1-11. http://dx.doi.org/10.1007/s12010-008-8468-9 PMid:19089650

Kallamadi, P.R., Ganga Rao Nadigatla, V.P.R., Mulpuri, S. 2015. Molecular diversity in castor (Ricinus communis L.). Industrial Crops and Products, vol. 66, p. 271-281. http://dx.doi.org/10.1016/j.indcrop.2014.12.061

Kanwal, M., Farhatullah-Rabbani, M.A., Iqbal, S., Fayyaz, L., Nawaz, I. 2014. The assessment of genetic diversity between and within Brassica species and their wild relative (Eruca sativa) using SSR markers. Pak. J. Bot., vol. 46, no. 4, p. 1515-1520.

Ogunniyi, D.S. 2006. Castor oil: a vital industrial raw material. Bioresour. technol., vol. 97, p. 1086-1091.

Pecina-Quintero, V., Anaya-López, J.L., Núnez-Colín, C.A., Zamarripa-Colmenero, A., Montes-García, N., Solís-Bonilla, J.L., Aguilar-Rangel, M.R. 2013. Assessing the genetic diversity of castor bean from Chiapas, México using SSR and AFLP markers. Industrial Crops and Products, vol. 41, p. 134-143. http:// dx.doi.org/10.1016/j.indcrop.2012.04.033

Polat, I., Turgutoglu, E., Kurt, S. 2015. Determination of genomic diversity within mutant lemon (Citrus limon L.) and mandarin (Citrus reticulata) using molecular markers. Pak. J. Bot., vol. 47, no. 3, p. 1095-1102.

Tan, M., Wu, K., Wang, L., Yan, M., Zhao, Z., Xu, J., Zeng, Y., Zhang, X., Fu, Ch., Xue, J., Wang, L., Yan, X. 2014. Developing and characterising Ricinus communis SSR markers by data mining of whole-genome sequences. Mol Breeding, vol. 34, p. 893-904. http://dx.doi.org/10.1007/s11032-014-0083-6

Vivodík, M., Balážová, Ž., Gálová, Z. 2014. RAPD analysis of the genetic diversity of castor bean. International journal of biological, veterinary, agricultural and food engineering, vol. 8, no. 7, p. 583-586. 